رديابى توان بيشينه سيستمهاى فتوولتائيك با استفاده از الكوريتم رسانايى افزايشى

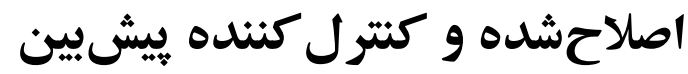

$$
\text { احمد دهقانزاده'، غلامرضا فراهانى '، محسن معبودى }
$$

'دانشجوى دكترى مهندسى برق، كروه فناورى هاى مخابراتى و فضايى، سازمان يثوهشهاى علمى و صنعتى ايران، a.dehghanzadeh@irost.ir

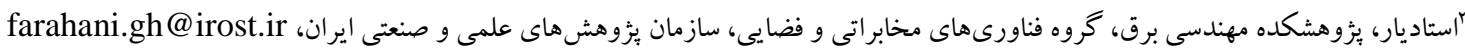

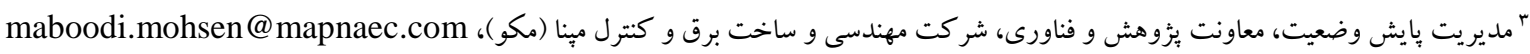

دريافت:

$$
\begin{aligned}
& \text { جكيده: در اين مقاله روش طراحى الكوريتم رسانايى افزايشى اصلاحشده به همراه كنترل كننده بيشبين مبتنى بر مدل به منظور رديابى } \\
& \text { توان بيشينه سيستم فتوولتائيك (PV) تشريح شده است. سيستم PV مورد بررسى، انرزى خورشيدى را از مازول PV با استفاده از مبدل توان }
\end{aligned}
$$

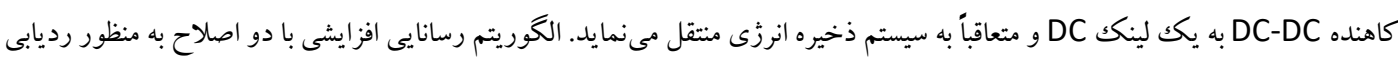

$$
\begin{aligned}
& \text { نقطه توان بيشينه بر روى منحنى P-V مازول خورشيدى نسبت به تغيير ات شر ايط محيطى در نظر گرفته شده است. براى اجتناب از يكك سيخنال } \\
& \text { كنترلى با مجموعه متناهى، مدل ميانگين سيستم PV محاسبه و حول نقطه توان بيشينه خطى سازى مى گردد. با طراحى كنترل كننده يويشيين، } \\
& \text { مزيتهاى آن نسبت به روش طر احى كنترل بيشبين با مدل كليدزنى مقايسه شده است. شبيهسازىها نشان مىدهد كه كنترل كننده ييشنهادى } \\
& \text { اين مقاله تغييرات توان بيشينه نسبت به تغييرات تابش خورشيد را با سرعت بيشتر و خطاى حالت ماند گار كمترى رديابى مى كند. } \\
& \text { كلمات كليدى: سيستم PV، كنترل كننده بيشبين مبتنى بر مدل، كنترل كننده بيشبين با مجموعه ورودى متناهى، رسانايى افزايشى. }
\end{aligned}
$$

\title{
Maximum Power Point Tracking of a Photovoltaic System Using Modified Incremental Algorithm and Model Predictive Control
}

\section{Ahmad Dehghanzadeh, Gholamreza Farahani, Mohsen Maboodi}

\begin{abstract}
In this paper a systematic methodology to design a modified incremental conductance and a model predictive control (MPC) for maximum power point tracking of a photovoltaic system is presented. The PV system includes a PV module that supplies a DC link and also an energy storage system using a buck DC-DC converter. The incremental conductance (INC) method with two modifications is employed for maximum power point tracking (MPPT) within P-V characteristic curve according to changes in weather condition. To avoid a finite set control signal, the average model of the PV system is analytically calculated and subsequently the model is linearized around MPP. Designing an MPC with continuous control set, its performance respect to finite control set MPC is compared. The simulations demonstrate that the proposed controller with augmented integrator could track the MPP faster and with less steady state error.
\end{abstract}

Keywords: PV system, model predictive control (MPC), finite control set MPC (FCS-MPC), Incremental conductance. 
نزديكك بهينه مى كند. تكرار اين فرايند در هر زمان نمونهبردارى موجب بهروزرسانى مدل در هر لحظه وكاهش خطاى مدلسازى به ويثه در

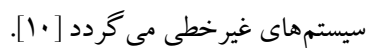
از طرف ديخر، كليدزنى ذاتى در مبدلهاى توان، منجر بهر به توسعه

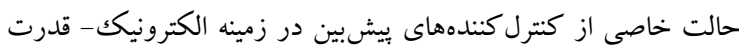

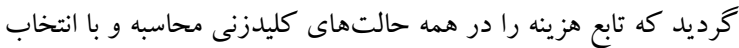
حالت كليدزنى متناظر با كمترين مقدار تابع هزينه، يكك الكوريتم ساده

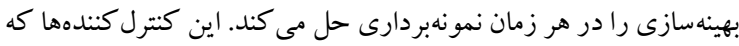
كنترل كننده بيشبين با مجموعه ورودى متناهى (FCS-MPC) ناميده مى -

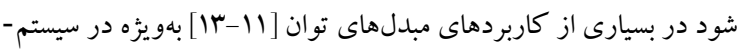
هاى PV [ استفاده شدهاند. اكرجه مقاله هاى متعددى كنترل كننده FCS-MPC حجم محاسبات در حالت افق بيشبينى طولانى و همجنين در كاربردهاى

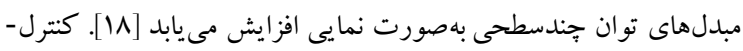
كننده FCS-MPC با فر كانس كليدزنى متغير كار مى كند كه منجر به ايجاد

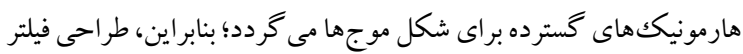
در سيستمهايى كه از FCS-MPC استفاده مى كنند با يك محس محدوديت اساسى مواجه مىشوند [9 19, •r]. در مقابل، CCS-MPC به دليل استفاده FCS- از يكك مدولاتور، با فر كانس ثابت كليدزنى كار مى كند. مى مت توان

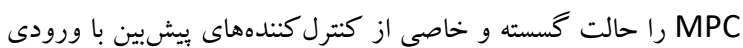

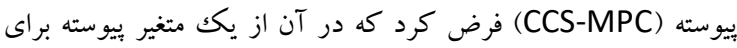

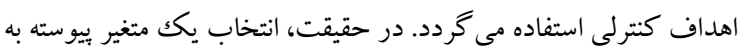
عنوان متغير قابل دستكارى از نظر كنترلى مطلوب است. در اين يروهش

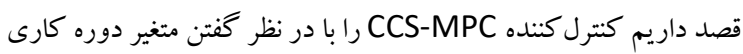
به عنوان متغير قابل دستكارى طراحى كنيم؛ در حالى كه

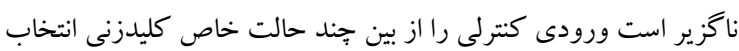
مىنمايد. در ادامه مقاله ابتدا سيستم PV مورد استفاده در اين بثزوهش معرفى و

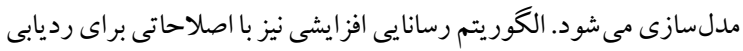

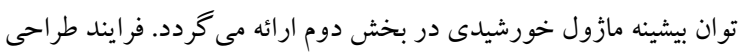

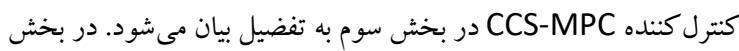

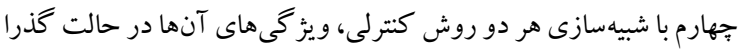

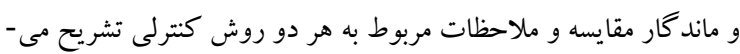

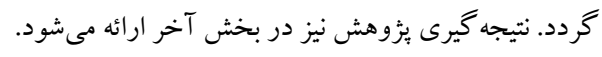

\section{PV تحليل سيستم}

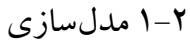

سيستم PV مورد استفاده در اين مقاله در شكل انشان داده شده است كه توان از طريق يكك مبدل كاهنده به سيستم ذخيره كننده انرزى منتقل

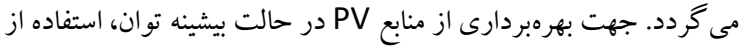

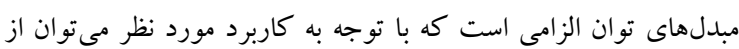

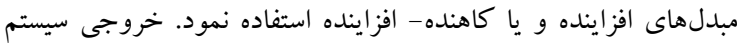

- 1 - - مقدمه

علىرغم كاهش قيمت سوختهاى فسيلى و قيمت تمام شده برق

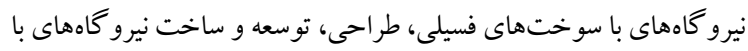

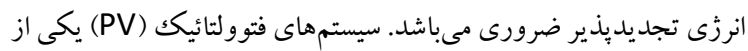

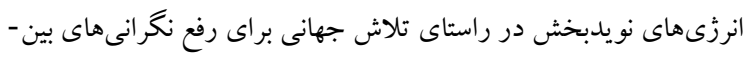

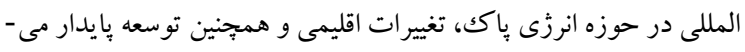

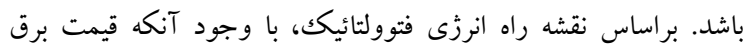

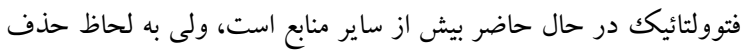

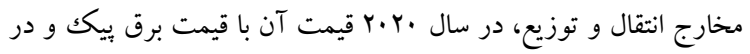

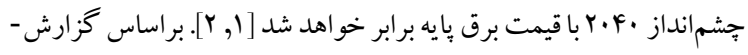

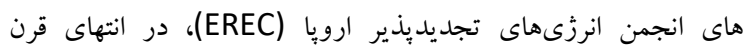

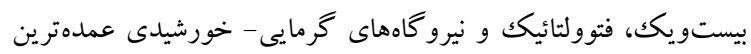

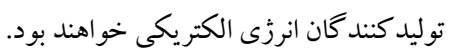
كرايش فزاينده صنعت برق به استفاده از سيستمهاى PV منجر به به به يزوهشهاى گستردهاى در اين حوزه گرديده است. هدف مشتر كك همه

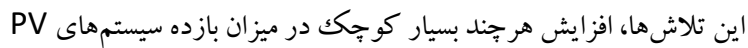

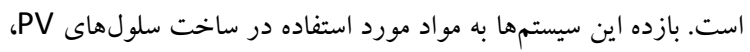
فرايند ساخت، توانايى در رديابى خورشيد، الكوريتم رديابى توان بيشينه و

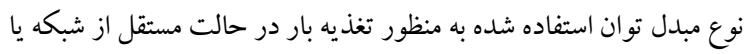
متصل به شبكه بستخى دارد. در اين مقاله، بنا داريم كه با طراحى كنترل-

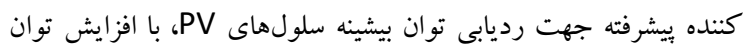

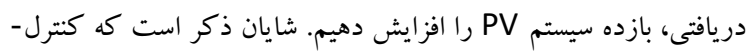

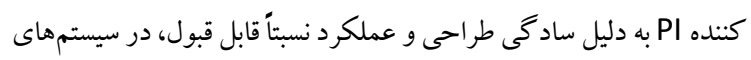

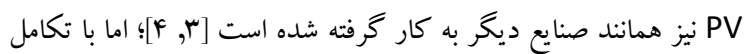

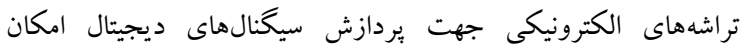

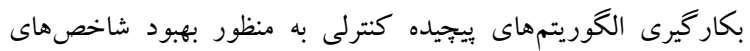
عملكردى در طراحى سيستمهاى PV فراهم شده است. تا كنون كنترل-

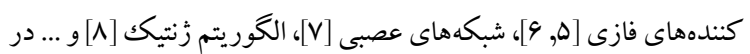
اين سيستمها مورد بررسى قرار گرفتهاند. با توجه به وجود مدل مدل نسبتاً دقيق، نوع ديخر از كنترل كنندهاى ييشرفته كه در دهه اخير در سيستمهاى الكترونيك- قدرت نظر هُزوهشكران را جلب نموده است، كنترل كننده

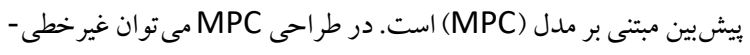

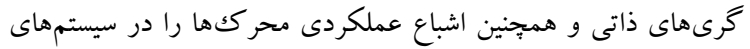

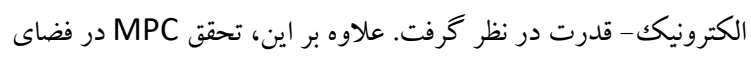

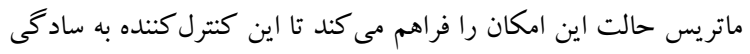

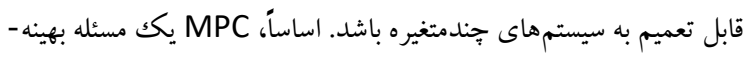

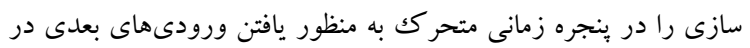

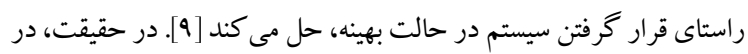
هر زمان نمونهبردارى، MPC مدل سيستم را در نقطه كار فعلى ساخته، متغيرهاى حالت را در زمانهاى بعدى محاسبه و با در نظر گرفتن آنها ديناميك فعلى سيستم را جهت رسيدن به حالت مطلوب در در آيندهاى بـاي 
همجنين d به عنوان دوره كارى از ميانگين گيرى از متغير U در بنجره زمانى متحر كى T حاصل مى گَردد.

$$
\left\{\begin{array}{l}
\frac{d v_{s}(t)}{d t}=\frac{1}{\mathrm{C}_{\mathrm{s}}}\left(i_{s}(t)-d(t) i_{L}(t)\right) \\
\frac{d i_{L}(t)}{d t}=\frac{1}{L}\left(-r i_{L}(t)+d(t) v_{s}(t)-V_{d c}\right)
\end{array}\right.
$$

معادله (9) مدل دقيقى از سيسم فتوولتائيك شكل انمىباشد؛ با اين

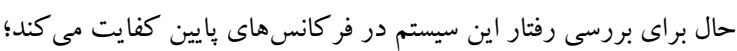

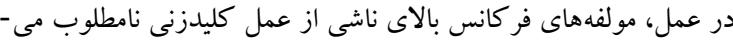

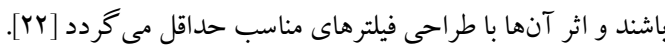

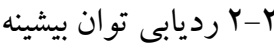

تغييرات دما و تابش، مختصات توان بيشينه را در منحنى جريان- ولتاز مازولهاى PV در محدوده وسيعى جابجا مى كند. با به كار گيرى مبدل

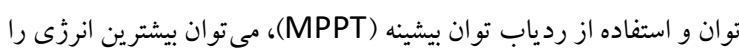
به صورت بلادرنك ذخيره نمود. روشهاى متعددى براى رديابى توان

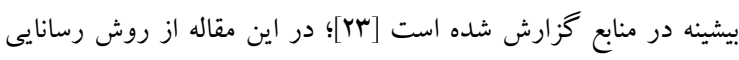
افزايشى (INC) با تغييراتى كه در ادامه ذكر مى گر ددد، استفاده شده است.

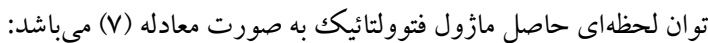

$$
p_{s}(t)=v_{s}(t) i_{s}(t)
$$

تغييرات توان نسبت به ولتار خروجى با معادله (A) بيان مى گردد كه در آن و و dg، رسانايى و رسانايى ديفرانسيلى مى باشند:

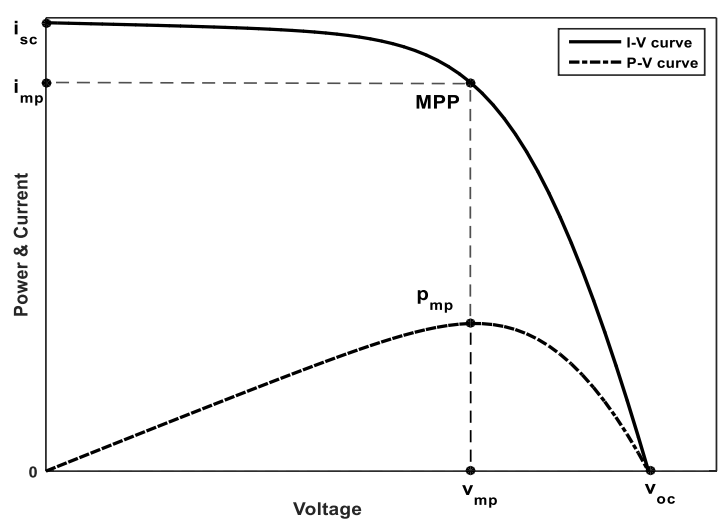

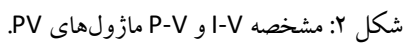

$$
\begin{aligned}
\frac{d p_{s}(t)}{d v_{s}(t)} & =v_{s}(t)\left(\frac{i_{s}(t)}{v_{s}(t)}+\frac{d i_{s}(t)}{d v_{s}(t)}\right) \\
& =v_{s}(t)(g(t)+d g(t))
\end{aligned}
$$

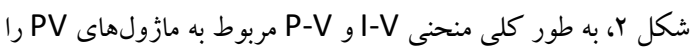
نشان مىدهد. نقاط جريان اتصال كو تاه (

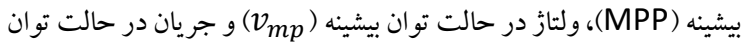
بيشينه (i

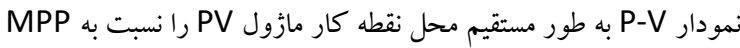

شكل ا با استفاده از باترى ثابت نكه داشته شده است؛ شايان ذكر است كه براى تغذيه شبكه DC مى توان از يك كنتر كنتده مستقل ديخر براى تنظيم

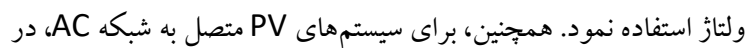
ادامه لينك DC مى توان از يكك اينورتر DC-AC با حلقه كتترلى مستقل

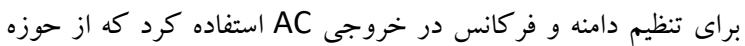

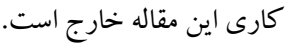

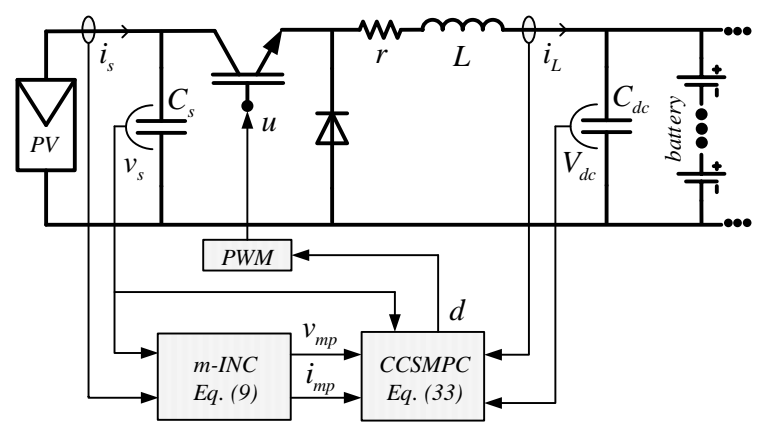
شكل 1: طرح كلى سيستم PV با كنترل كنده بيشنهادى براى رديابى توان بيشينه.

همانطور كه در شكل 1 مشاهده مى گردد، ولتازٔ و جريان مازول PV

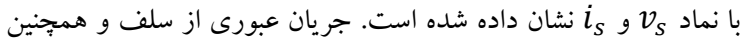

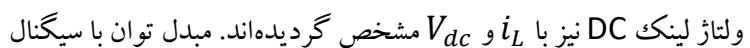

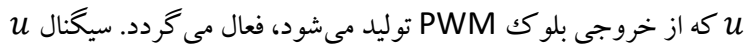

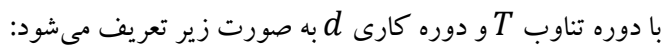
$u(t)=\left\{\begin{array}{cc}1 & 0 \leq t<d T \\ 0 & d T \leq t \leq T\end{array} \quad u(t-T)=u(t) \forall t\right.$

با اعمال قانون كيرشهف در دو حالت كليدزنى $u=1$ و $u=1$ و

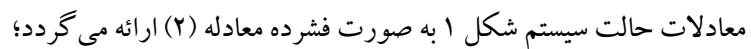
اين معادله با قابليت مدل كردن طبيعت كليدزنى مبدل توان، مدل كليدزنى يا مدل دقيق ناميده مى شود:

$$
\left\{\begin{array}{l}
-i_{s}(t)+\mathrm{C}_{\mathrm{s}} \frac{d v_{s}(t)}{d t}+u(t) i_{L}(t)=0 \\
-u(t) v_{s}(t)+r i_{L}+L \frac{d i_{L}(t)}{d t}+V_{d c}=0
\end{array}\right.
$$

در مهندسى كنترل، مطلوب است كه سيكنال كنترلى يكك متغير

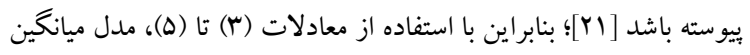
سيستم شكل ا به صورت معادله (و) بدست مى آيد.

$$
\begin{aligned}
\left\langle x(t)_{0}\right\rangle(\mathrm{t}) & =\frac{1}{T} \int_{t-T}^{t} x(\tau) d \tau \\
\left\langle\frac{d x(t)}{d t}\right\rangle_{0}(t) & =\frac{d}{d t}\langle x(t)\rangle_{0}(t)
\end{aligned}
$$

$$
\langle x(t) u(t)\rangle_{0}(t) \approx\langle x(t)\rangle_{0}(\mathrm{t})\langle u(t)\rangle_{0}(\mathrm{t})
$$
شايان ذكر است كه نماد

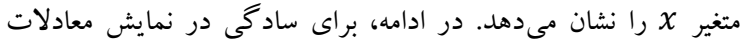

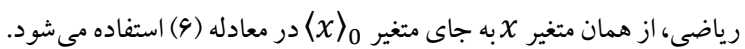




$$
i_{L m p}(t)=\frac{i_{m p}(t)}{d_{m p}(t)}
$$

با آكاهى از مقادير نامى حالتها و ورودى در نقطه كار MPP، مدل

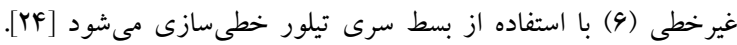
همانطور كه معادله (Ir) نشان مى دهد،

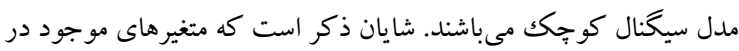

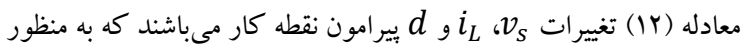

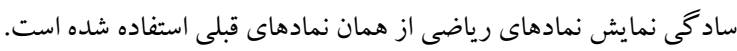

$$
\left\{\begin{array}{l}
\frac{d \mathrm{x}(t)}{d t}=A_{c}(t) x(t)+B_{c}(t) d(t) \\
y(t)=C_{c}(t) x(t)
\end{array}\right.
$$

$$
\left\{\begin{array}{l}
A_{c}=\left[\begin{array}{cc}
\frac{d g_{m p}(t)}{\mathrm{C}_{\mathrm{s}}} & -\frac{d_{m p}(t)}{\mathrm{C}_{\mathrm{s}}} \\
\frac{d_{m p}(t)}{L} & -\frac{\mathrm{R}}{L}
\end{array}\right], B_{c}=\left[\begin{array}{c}
-\frac{i_{L m p}(t)}{\mathrm{C}_{\mathrm{s}}} \\
\frac{v_{m p}(t)}{L}
\end{array}\right] \\
C_{c}=\left[\begin{array}{ll}
1 & 0
\end{array}\right]
\end{array}\right.
$$

با توجه به اينكه معادله (^) در MPP صفر مىباشد، مقدار

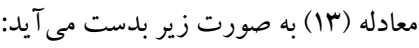

$$
d g_{m p}(t)=\left.\frac{d i_{s}(t)}{d v_{s}(t)}\right|_{m p}=-\frac{i_{m p}(t)}{v_{m p}(t)}
$$

مدل سيخنال كوجٍك در فضاى گسسته نيز به صورت زير محاسبه

$$
\left\{\begin{array}{l}
x(k+1)=A_{d} x(k)+B_{d} d(k) \\
y(k)=C_{d} x(k)
\end{array}\right.
$$

كه ماتريسهاى حالت، ورودى و خروجى در فضاى گسسته در

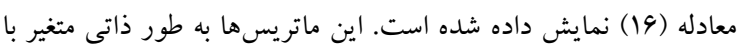
زمان مىباشند ولى در مدت زمان نمونهبردارى ثابت فرض شدهاند.

$$
\left\{\begin{array}{l}
A_{d}=\exp \left(A_{c} T_{s}\right), B_{d}=\int_{0}^{T_{s}} \exp \left(A_{c} \tau\right) B_{c} d \tau \\
C_{d}=C_{c}
\end{array}\right.
$$

$$
\text { r-r ب بيشبينى }
$$

در اين بخش، مقادير بيشينى شده حالتها و خروجى سيستم PV بر بركيت

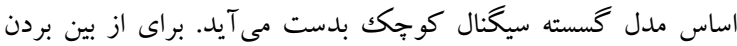

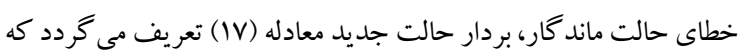

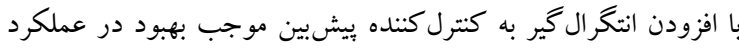

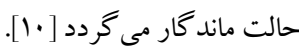

$$
\begin{aligned}
& x_{a}(k)=\left[\begin{array}{ll}
\Delta x(k)^{T} & y(k)
\end{array}\right]^{T} \\
& \Delta x(k)=x(k)-x(k-1) \\
& \text { بدين ترتيب مدل افزونه سيستم PV به صورت زير مىباشد: }
\end{aligned}
$$

تعيين مىنمايد؛ درحقيقت، اكر شيب نمودار مثبت باشد، نقطه كار در

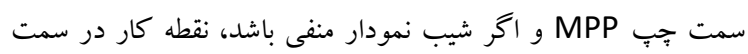

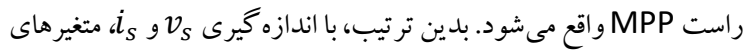

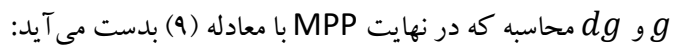

$$
\left\{\begin{array}{l}
v_{m p}(t)=v_{s}(t)+V_{i n c} \operatorname{sign}(g(t)+d g(t)) \\
i_{m p}(t)=i_{s}(t)-I_{i n c} \operatorname{sign}(g(t)+d g(t))
\end{array}\right.
$$

در اين ئروش، دو تغيير در روش INC ايجاد شده است. اول اينكه

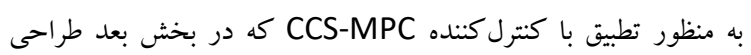

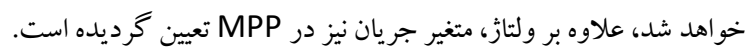

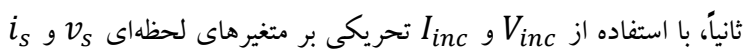

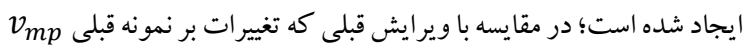
و

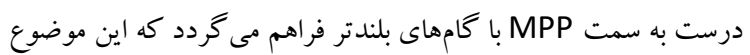

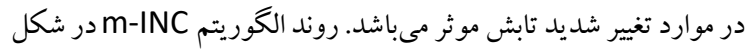

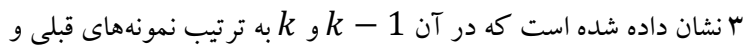

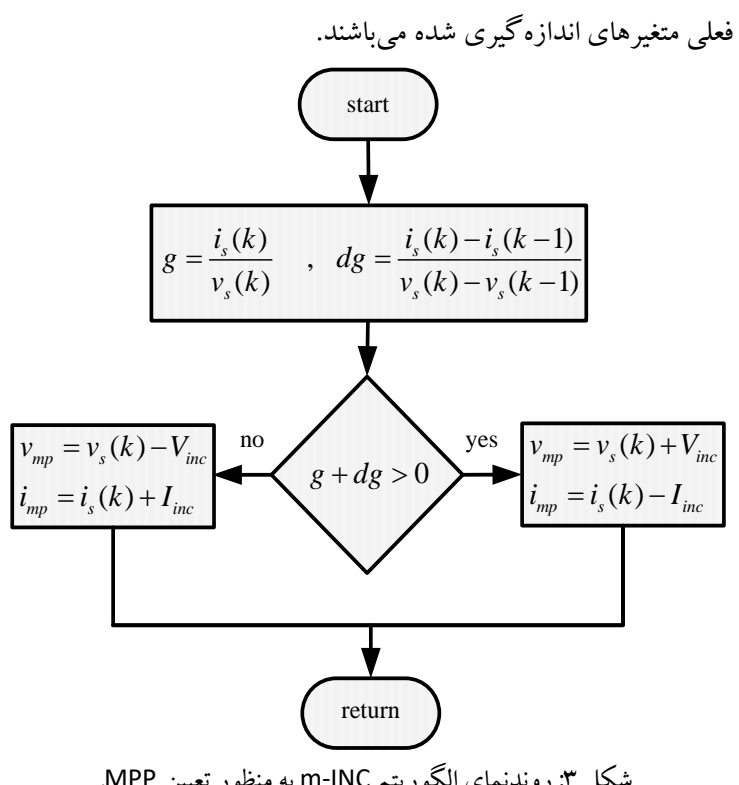

ب- طراحى كنترل كننده CCS-MPC

$$
\text { r-1 مدل سيخنال كو جك }
$$

از آنجايى كه مدل ميانكين معادله (9) يكك سيستم غيرخطى است،

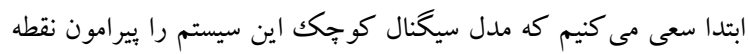

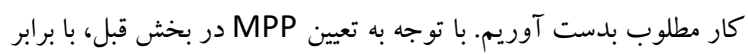
صفر قرار دادن تغييرات حالتها در مدل (9)، نقطه كار سيستم با فرض قرار كرفتن مازول PV در نقطه توان بيشينه بدست مى آ يد:

$$
d_{m p}(t)=\frac{V_{d c}+\sqrt{V_{d c}{ }^{2}+4 r v_{m p}(t) i_{m p}(t)}}{2 v_{m p}(t)}
$$




$$
R_{s}=\left[\begin{array}{llll}
1 & 1 & \cdots & 1
\end{array}\right]^{T} v_{m p}
$$

هدف كنتر كنده MPC كمينه نمودن خطاى بين مقادير خروجى و

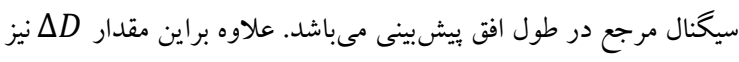

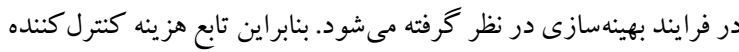

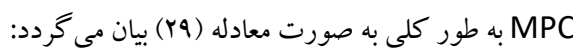

$$
J=\left(R_{s}-Y\right)^{T}\left(R_{s}-Y\right)+\Delta D^{T} R_{w} \Delta D
$$

كه در آن

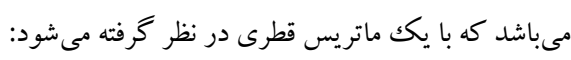

$$
R_{w}=r_{w} I_{N_{c} \times N_{c}}
$$

مقدار توجهى كه به اندازه $D D$ يرداخته مىشود با اندازه

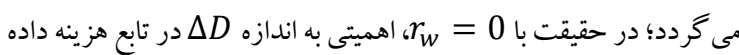

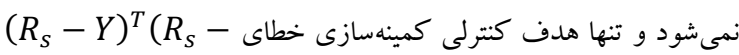

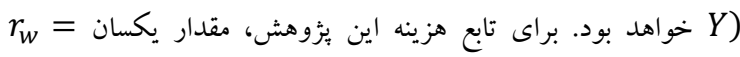

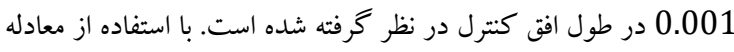

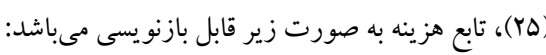

$$
\begin{aligned}
& J=\left(R_{s}-F x_{a}(k)\right)^{T}\left(R_{s}-F x_{a}(k)\right)- \\
& 2 \Delta D^{T} \Phi^{T}\left(R_{s}-F x_{a}(k)\right)+\Delta D^{T}\left(\Phi^{T} \Phi+R_{w}\right) \Delta D \\
& \text { ه بدست مى آيد: D } \\
& \frac{\partial J}{\partial \Delta D}=-2 \Phi^{T}\left(R_{s}-F x_{a}(k)\right)+2\left(\Phi^{T} \Phi+R_{w}\right) \Delta D \quad \text { (rr) }
\end{aligned}
$$

در نهايت مقدار بهينه تغييرات دوره كارى به صورت معادله (Tr)

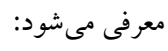

$$
\Delta D=\left(\Phi^{T} \Phi+R_{w}\right)^{-1} \Phi^{T}\left(R_{s}-F x_{a}(k)\right)
$$

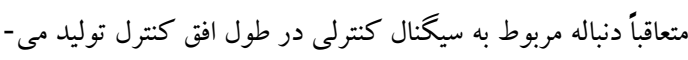
كردد كه درايه اول براى دوره كارى اجرا مى گردد.

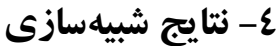

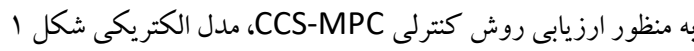

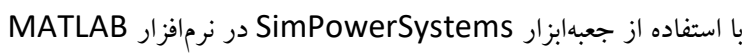
شبيهسازى مى گردد. مقدار عناصر موجود در مدار براى مطالعات شبيه -

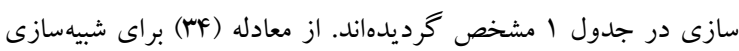

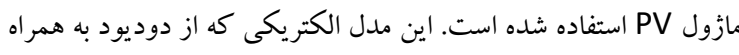

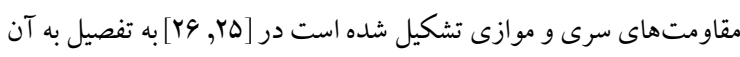

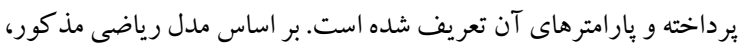

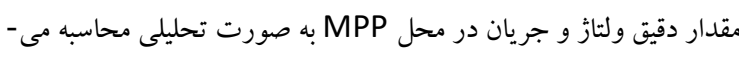

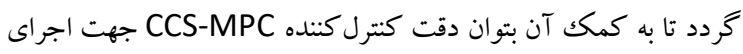
فرامين m-INC MPPT را صحه كذارى نمود.

$$
\left\{\begin{array}{l}
x_{a}(k+1)=A_{a} x_{a}(k)+B_{a} \Delta d(k) \\
y(k)=C_{a} x_{a}(k)
\end{array}\right.
$$

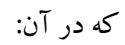

$$
\begin{aligned}
& \Delta d(k)=d(k)-d(k-1) \\
& \left\{\begin{array}{l}
A_{a}=\left[\begin{array}{cc}
A_{d} & 0 \\
C_{d} A_{d} & 1
\end{array}\right], B_{a}=\left[\begin{array}{c}
B_{d} \\
C_{d} B_{d}
\end{array}\right] \\
C_{a}=\left[\begin{array}{lll}
0 & 0 & 1
\end{array}\right]
\end{array}\right.
\end{aligned}
$$

با استفاده از معادله (19)، نمونههاى آينده خروجى و حالتهاى

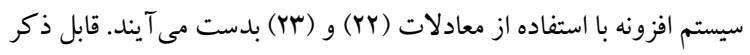

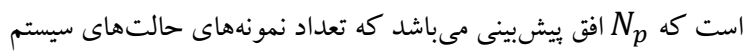

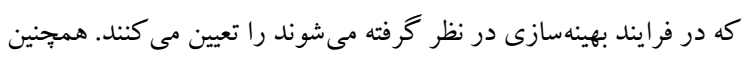
N N $N_{C}$ در طول آن توليد مىنمايد.

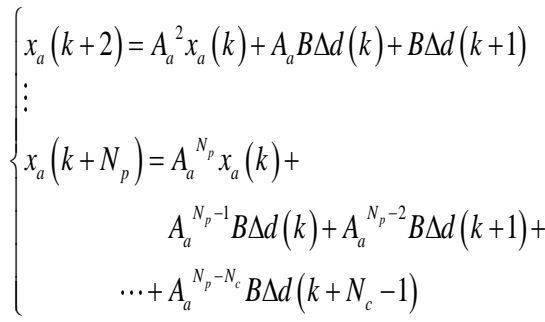

$$
y\left(k+N_{p}\right)=C_{a} x_{a}\left(k+N_{p}\right)
$$

با تعريف بردارهاى معادله (YY)، تمامى متغيرهاى حالت و خروجى نمونهاى آتى در افق بيشبينى به صورت فشرده (YD) ارائه مى گرددد: $\left\{\begin{array}{l}Y=\left[\begin{array}{llll}y(k+1) & y(k+2) & \ldots & y\left(k+N_{p}\right)\end{array}\right]^{T} \\ \Delta D=\left[\begin{array}{llll}\Delta d(k) & \Delta d(k+1) & \ldots & \Delta d\left(k+N_{c}-1\right)\end{array}\right]^{T}\end{array}\right.$

$$
Y=F x_{a}(k)+\Phi \Delta D
$$

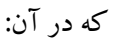

$$
\begin{aligned}
F & =\left[\begin{array}{cccc}
C_{a} A_{a} & C_{a} A_{a}^{2} & \ldots & C_{a} A_{a}^{N_{p}}
\end{array}\right]^{T} \\
\Phi & =\left[\begin{array}{cccc}
C_{a} B_{a} & 0 & \cdots & 0 \\
C_{a} A_{a} B_{a} & C_{a} B_{a} & \cdots & 0 \\
\vdots & \vdots & \cdots & 0 \\
C_{a} A_{a}^{N_{p}-1} B_{a} & C_{a} A_{a}^{N_{p}-2} B_{a} & \cdots & C_{a} A_{a}^{N_{p}-N_{c}} B_{a}
\end{array}\right]
\end{aligned}
$$

$$
\text { r-r ب بهينهسازى }
$$

براى كنترل خروجى مازول PV در MPP، ورودى مرجع

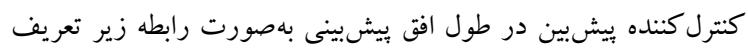
مىشود: - مي 
است كه فيلترهاى يكسانى جهت پالايش مولفههاى فر كانس هاى بالا در

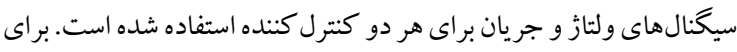

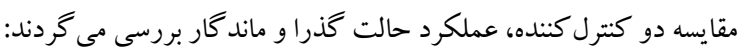
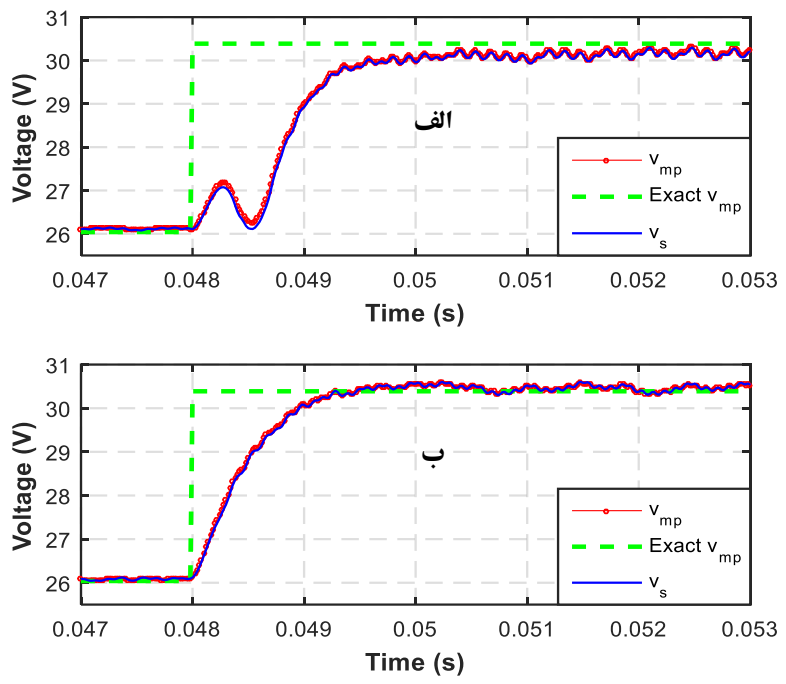

شكل F: ولتاز خروجى مازول PV در حالت تغيير نا گهانى در شدت تابش: الف)

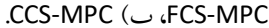

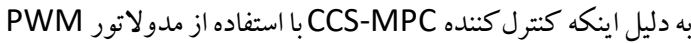

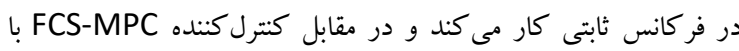

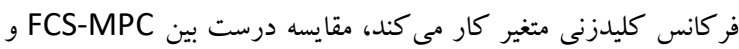

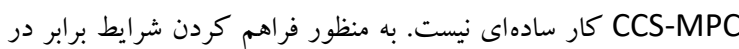

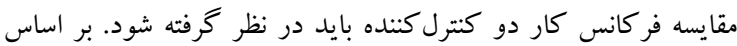

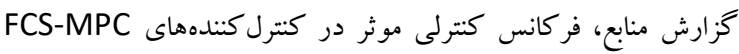

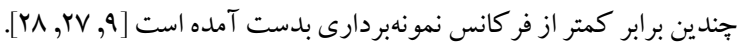

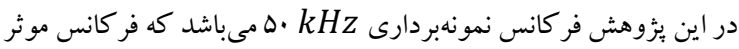

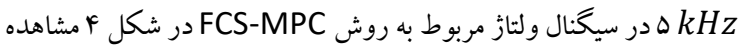
شده است. بنابر اين فر كانس مشابه kHz ه براى كليدزنى PWM انتخاب شده است تا بتوان مقايسه منصفانه ترى صورت بذ بذيرد.

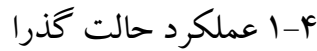

براى ارزيابى عملكرد حالت گذخراى دو كنترل كننده، ابتدا بايد مقدار

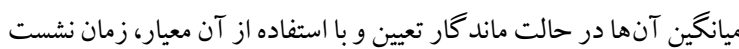

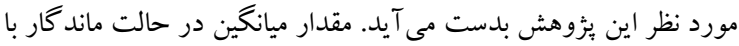

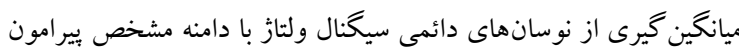
نقطه تعادل و بدون گذر از آن بدست مى آيد. اين مقدار براى

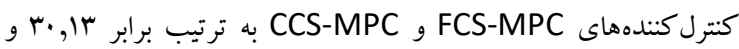

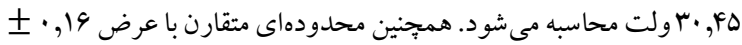

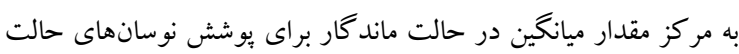

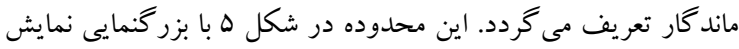

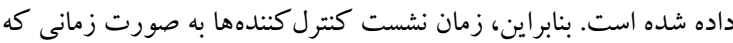

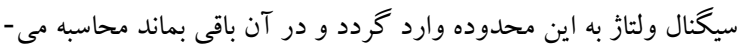

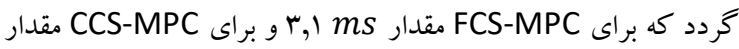

$$
\begin{aligned}
& =\frac{I_{s}}{1+R_{s} G_{p}} \\
& -\left\{\frac{n_{1} V_{T}}{a R_{s}} \text { Lambert } w\left[\frac{I_{s 1} a R_{S}}{n_{1} V_{T}\left(1+R_{S} G_{p}\right)} \exp \left(\frac{V_{s}+I_{p h} R_{s}+I_{s 1} a R_{s}}{n_{1} V_{T}\left(1+R_{S} G_{p}\right)}\right)\right]\right. \\
& \left.-\frac{I_{s 1}}{\left(1+R_{S} G_{p}\right)}\right\} \\
& -\left\{\frac{n_{2} V_{T}}{R_{S}} \text { Lambert } w\left[\frac{I_{S 2} R_{S}}{n_{2} V_{T}\left(1+R_{s} G_{p}\right)} \exp \left(\frac{V_{s}+I_{p h} R_{S}+I_{s 2} R_{S}}{n_{2} V_{T}\left(1+R_{S} G_{p}\right)}\right)\right]\right. \\
& \left.-\frac{I_{s 2}}{\left(1+R_{s} G_{p}\right)}\right\} \\
& \text { كه در آن تابع لمبرت به صورت رابطه (هـ) تعريف مىشود: } \\
& \text { if } \begin{aligned}
y e^{y}=u \quad \leftrightarrow & y \\
& =\text { Lambert } w(u)
\end{aligned}
\end{aligned}
$$

\begin{tabular}{|c|c|}
\hline $10 \cdot u F$ & خازن ورودى (C) \\
\hline •, ० mH و $1 \mathrm{~m} \Omega$ & سلف (r,L) \\
\hline $10 \cdot u F$ & خازن لينك DC \\
\hline$\approx \| r V$ & ولثاز باترى (V \\
\hline$\varepsilon \cdot \Omega$ & بارخروجى \\
\hline$\circ \mathrm{kHz}$ & فر كانس كليدزنى \\
\hline$r \cdot u s$ & زمان نمونهبردارى (T) \\
\hline
\end{tabular}

جدول ا: مشخصات سيستم PV مورد مطالعه در اين يزوهش

براى مقايسه كنترل كننده بيشبين بيشنهادى با كنترل كننده بيشبين

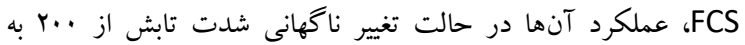

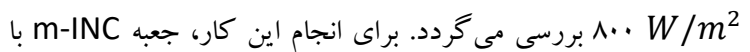

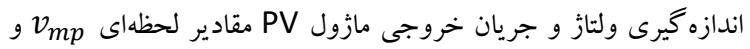
با

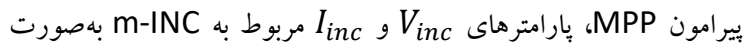

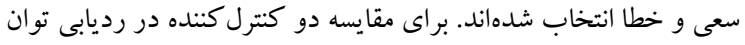
بيشينه، سيكنال مرجع توليدى توسط m-INC با استفاده از كنترل كنندههاى FCS- رديابى مى گردند. طر احى كنترل كننده CCS-MPC, و FCS-MPC

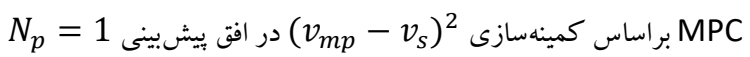

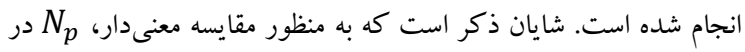

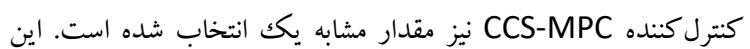
روش كه با استفاده از مدل كليدزنى مبدل طراحى مى شود در [11] تشريح

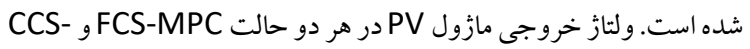
MPC

براى ارزيابى عملكرد الكوريتم m-INC، مقدار دقيق

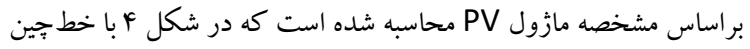

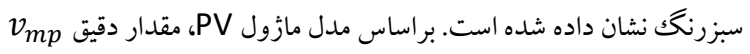

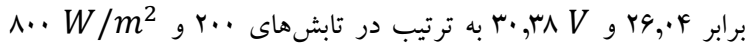

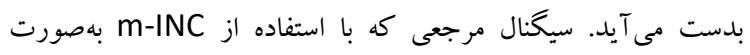

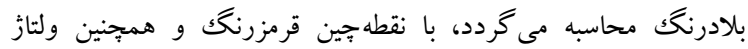
خروجى مازول PV با منحنى آبى رنگك نمايش داده شده است. شايان ذكر فردئ 


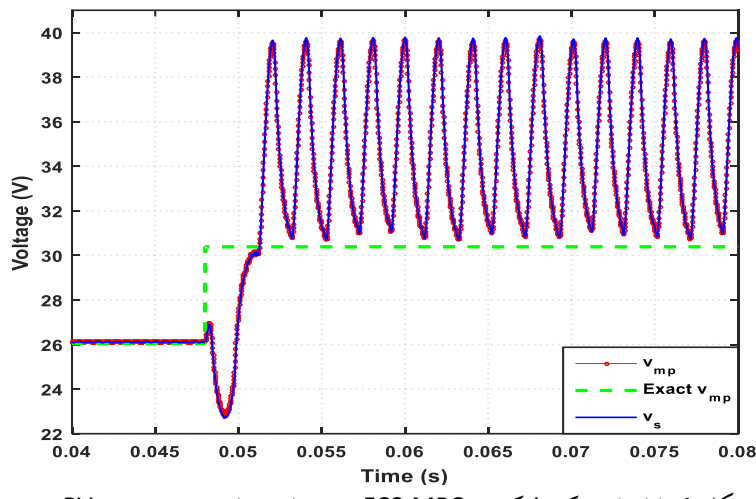

شكل 9: نايايدارى كنترل كنند 0.075 PCS-MPC در رديابى توان بيشينه سيستم PV در

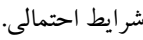

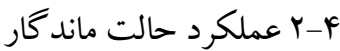

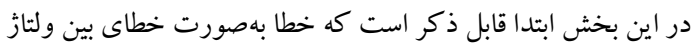

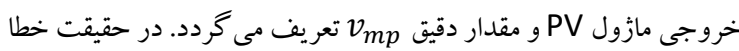
در مهندسى كتترل، خطاى بين سيكنال مرجع و خروجى سيستم در نظر

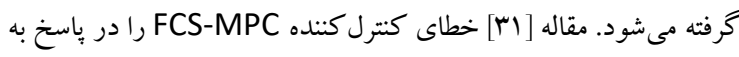
سيكنال هاى مرجع مختلف بدست آورده است. برواضح است كه خطا در برد

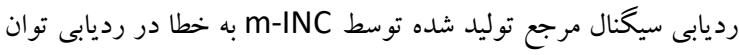

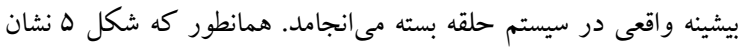
مى دهد، مقدار دقيق

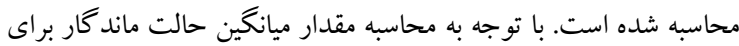

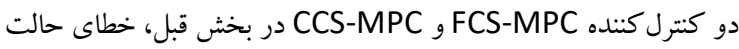

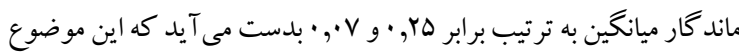

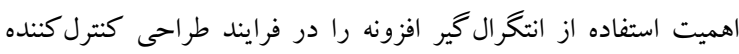

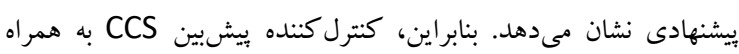

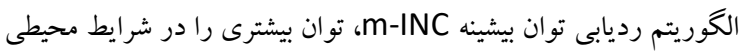

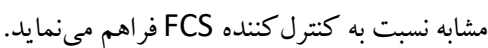
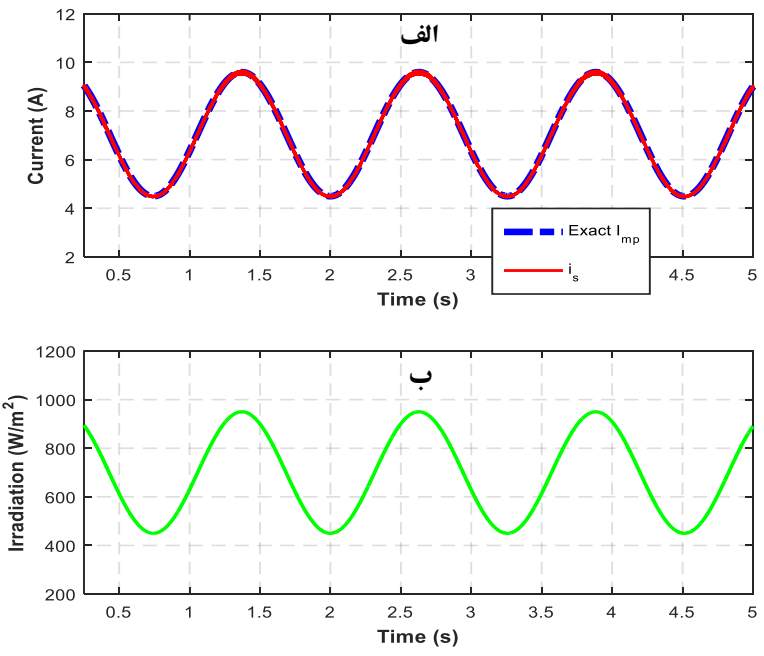

شكل V: رديابى توان بيشينه توسط كنتر كننده CCS-MPC نسبت به تغييرات تابش. الف) جريان خروجى مازول PV و جريان مرجع در MPP، بو ب) سيخنال تابش. 1,f ms

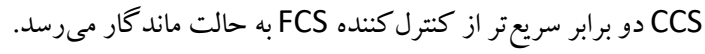
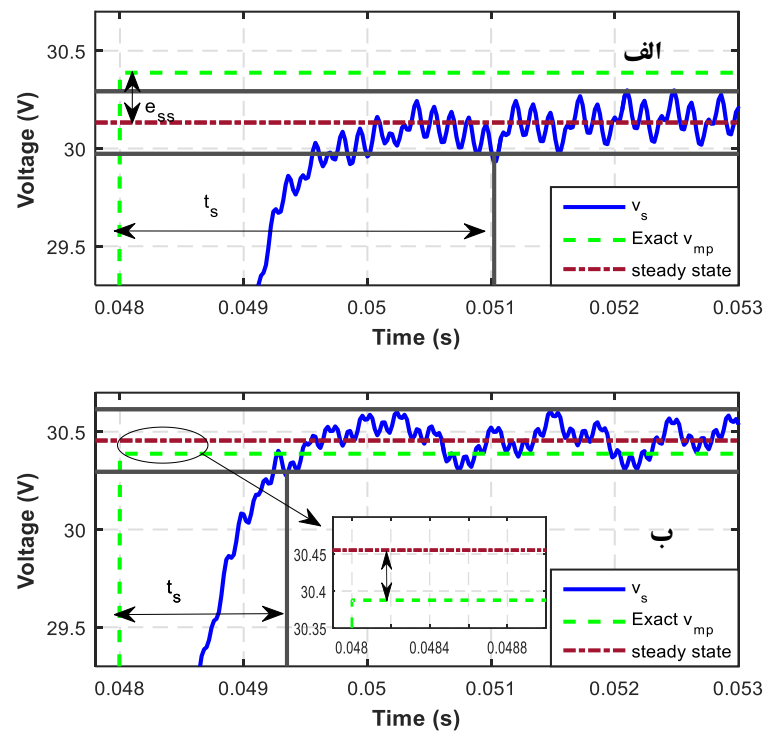

شكل ه: تعيين محدوده نو سان حالت ماند كار ولتاز خروجى مازول PV جهت

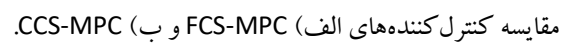

با وجود يخوهشهاى متعدد در زمينه يِيادهسازى FCS-MPC،

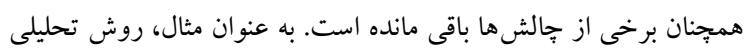

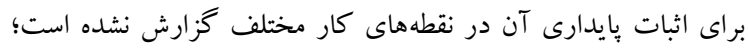

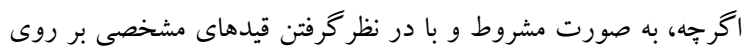

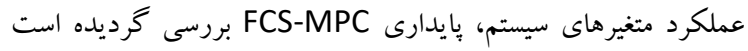

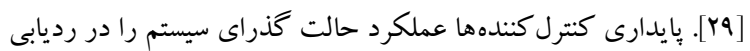
توان بيشينه مازول PV تحت تاثير قرار مىدهد. همانطور كه شكل هـ نشان

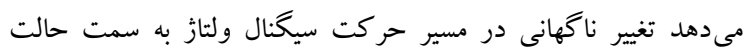
ماند كار براى كنترل كننده FCS-MPC مشاهده مى گرد دمد. علاوه براين،

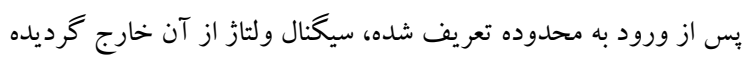
كه مى توان آن را به عنوان فراجهش در عملكرد اين كنترل كنتده در نظر

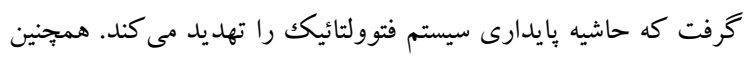

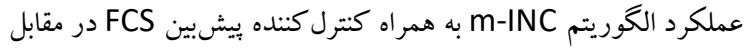

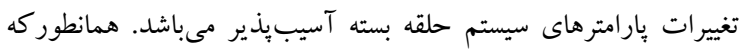

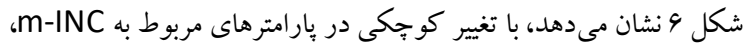

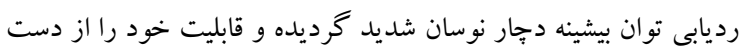

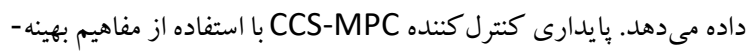

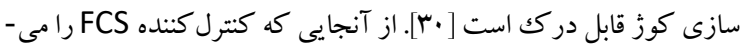

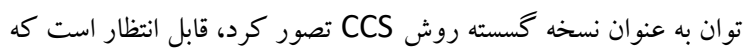
كنترل كننده CCS-MPC مقاومت بيشترى در برابر تغييرات پارامترهاي

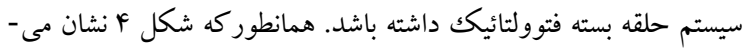
دهد، روش CCS محل دقيق MPP را بدون تغيير مسير طى مى كند. 
رديابى توان بيشينه، سيكنال ورودى مرجع را براى كنترل كننده بيشبين

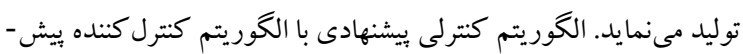

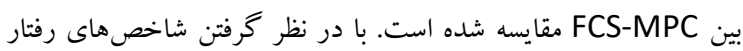

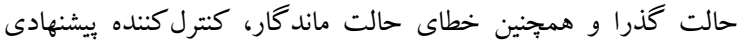
عملكرد بهترى را در رديابى توان بيشينه نشان داده است. نقاط قوت هان

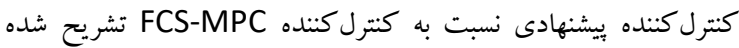
است؛ در حقيقت با ارائه فر كانس كليدزنى ثابت، قابليت در نظر كرفتن قيدهاى محدودكننده، قابليت تعميم به سيستمهاى جندمتئيره و و ...،

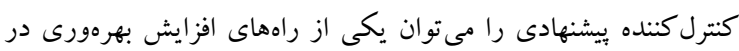

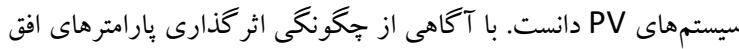

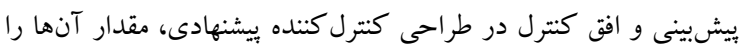

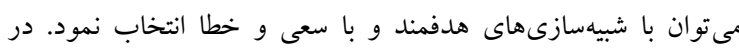

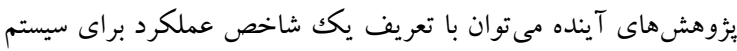

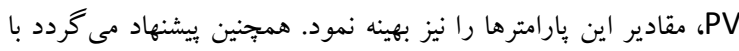

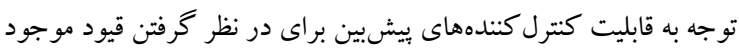

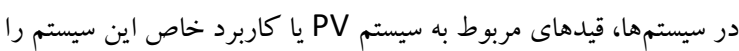

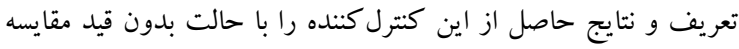

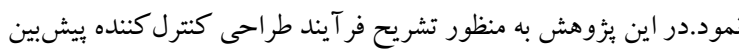

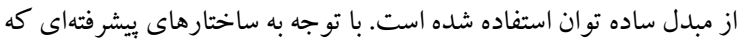

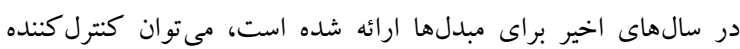

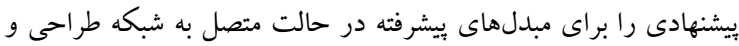

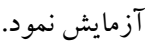

\section{مراجع}

[1] P. Frankl, S. Nowak, M. Gutschner, S. Gnos, and T. Rinke, "Technology roadmap: solar photovoltaic energy," International Energy Association, 2010.

[2] A. Lopez, B. Roberts, D. Heimiller, N. Blair, and G. Porro, "US renewable energy technical potentials: a GIS-based analysis," Contract, vol. 303, pp. 275-3000, 2012.

[3] M. A. G. De Brito, L. Galotto, L. P. Sampaio, G. d. A. e Melo, and C. A. Canesin, "Evaluation of the main MPPT techniques for photovoltaic applications," IEEE transactions on industrial electronics, vol. 60, pp. 1156-1167, 2013.

[4] R. Kadri, J.-P. Gaubert, and G. Champenois, "An improved maximum power point tracking for photovoltaic grid-connected inverter based on voltage-oriented control," IEEE Transactions on Industrial Electronics, vol. 58, pp. 66-75, 2011.

[5] B. N. Alajmi, K. H. Ahmed, S. J. Finney, and B. W. Williams, "Fuzzy-logic-control approach of a modified hill-climbing method for maximum power point in microgrid standalone photovoltaic system," IEEE Transactions on Power Electronics, vol. 26, pp. 1022-1030, 2011.

[6] A. Al Nabulsi and R. Dhaouadi, "Efficiency optimization of a DSP-based standalone PV system using fuzzy logic and dual-MPPT
عملكرد كنترل كننده ييشنهادى اين مقاله در رديابى توان بيشينه نسبت به تغييرات سينوسى تابش در شكل V رسم شده است. سيخنال لحظهاى m- و همجينين جريان مرجعى كه الكوريتم

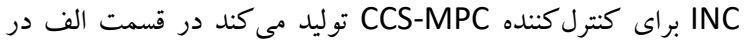

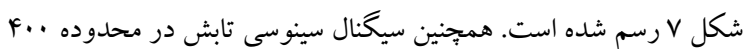

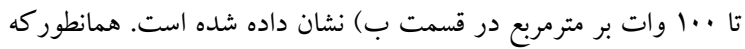
ملاحظه مى گردد كنترل كننده CCS-MPC در برداشت بهينه انرزى قابل حصول مازول PV موفق عمل كرده است. شكل V لبه خوبى رابطه تقريباً خطى تغييرات تابش و جريان را منعكس نموده است.

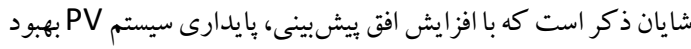

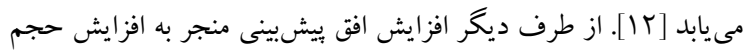

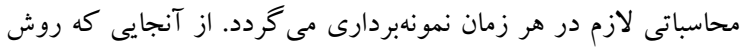
FCS

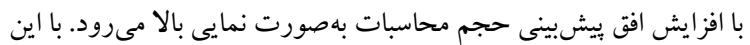

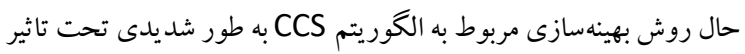

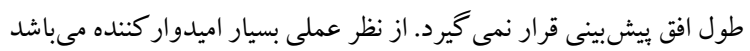

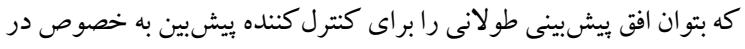

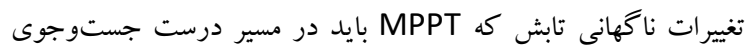
حر كت كند، در نظر گرفت. اخرجه افز ايش طول افق ييش بينى تاثير

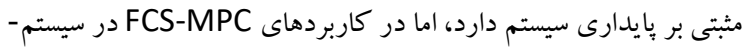

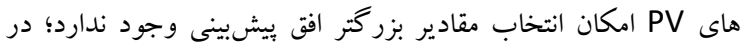

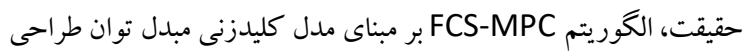

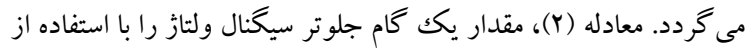

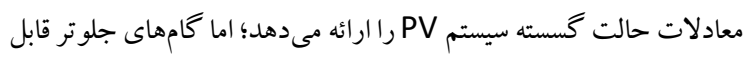
محاسبه نمىباشند زيرا مقدار محار

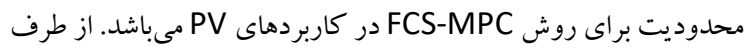

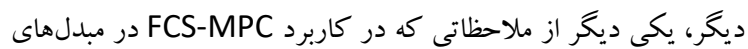

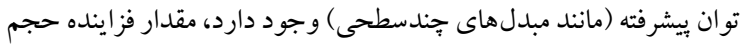
محاسبات با توجه به افزايش تعداد كليدها در مبدل و در نتيجه افزايش نمايى حالتهاى كليدزنى مىباشد. همجنين، روش FCS-MPC ذاتاً تقادر

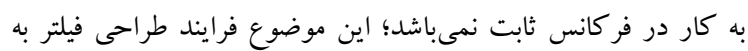

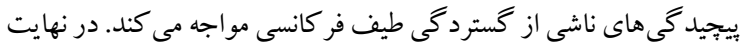

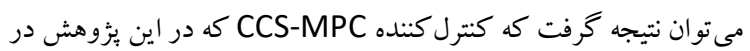
جهت رديابى توان بيشينه براى سيستمهاى PV ارائه شده است كاستىهاى

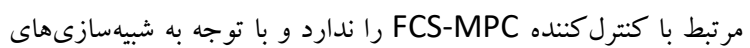

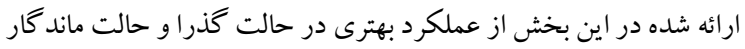

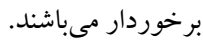

\section{0- نتيجه كيرى}

در اين مقاله كنترلكننده CCS-MPC در يك سيستم PV شامل

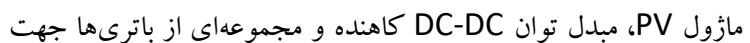

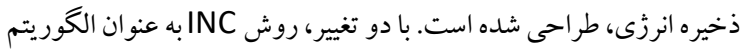


inverter," IEEE Transactions on Industrial Electronics, vol. 63, pp. 4180-4186, 2016.

[19] J. I. Leon, S. Kouro, L. G. Franquelo, J. Rodriguez ,and $\mathrm{B}$. Wu, "The Essential Role and the Continuous Evolution of Modulation Techniques for Voltage-Source Inverters in the Past, Present, and Future Power Electronics," IEEE Transactions on Industrial Electronics, vol. 63, pp. 2688-2701, 2016.

[20] M. G. Judewicz, S. A. Gonzalez, N. I. Echeverria, J. R. Fischer, and D. O. Carrica, "Generalized Predictive Current Control (GPCC) for Grid-Tie Three-Phase Inverters."

[21] J. Sun and H. Grotstollen, "Averaged modelling of switching power converters: reformulation and theoretical basis," in Power Electronics Specialists Conference, 1992. PESC'92 Record., 23rd Annual IEEE, 1992, pp. 1165-1172.

[22] S. Bacha, I. Munteanu, and A. I. Bratcu, Power Electronic Converters Modeling and Control vol. 5: Springer, 2014.

[23] A. Dehghanzadeh and G. Farahani, "A Survey on Maximum Power Point Tracking Techniques in Solar Installations," presented at the International Conference on New Research Achievements in Electrical and Computer Engineering, Tehran, 2016.

[24] H. K. Khalil, "Noninear Systems," Prentice-Hall, New Jersey, vol. 2, p. 5.1, 1996.

[25] A. Dehghanzadeh, G. Farahani, and M. Maboodi, "A novel approximate explicit double-diode model of solar cells for use in simulation studies," Renewable energy, vol. 103, pp. 468477, 2017.

[26] A. Dehghanzadeh, G. Farahani, H. Vahedi, and K. Al-Haddad, "Explicit double-exponential modeling methods for photovoltaic cells," in Industrial Technology (ICIT), 2017 IEEE International Conference on, 2017, pp. 423-428.

[27] P. Lezana, R .Aguilera, and D. E. Quevedo, "Model predictive control of an asymmetric flying capacitor converter," IEEE Transactions on Industrial Electronics, vol. 56, pp. 1839-1846, 2009.

[28] J. Rodriguez and P. Cortes, Predictive control of power converters and electrical drives vol. 40: John Wiley \& Sons, 2012.

[29] R. P. Aguilera and D. E. Quevedo, "Stability analysis of quadratic MPC with a discrete input alphabet," IEEE Transactions on Automatic Control, vol. 58, pp. 3190-3196, 2013.

[30] J. M. Maciejowski, Predictive control: with constraints: Pearson education, 2002.

[31] R. P. Aguilera, P. Lezana, and D. E. Quevedo, "Finite-control-set model predictive control with improved steady-state performance," IEEE Transactions on Industrial informatics, vol. 9, pp. 658-667, 2013. control," IEEE Transactions on Industrial Informatics, vol. 8, pp. 573-584, 2012.

[7] W.-M. Lin, C.-M. Hong, and C.-H. Chen, "Neural-network-based MPPT control of a standalone hybrid power generation system," IEEE Transactions on Power Electronics, vol. 26, pp. 3571-3581, 2011.

[8] M. Dahmane, J. Bosche, A. El-Hajjaji, and X. Pierre, "MPPT for photovoltaic conversion systems using genetic algorithm and robust control," in 2013 American Control Conference, 2013, pp. 6595-6600.

[9] C. Bordons and C. Montero, "Basic principles of MPC for power converters: Bridging the gap between theory and practice," IEEE Industrial Electronics Magazine, vol. 9, pp. 31-43, 2015.

[10] L. Wang, Model predictive control system design and implementation using MATLAB $®$ : Springer Science \& Business Media, 2009.

[11] J. Rodriguez, M. P. Kazmierkowski, J. R. Espinoza, P. Zanchetta, H. Abu-Rub, H. A. Young, et al., "State of the art of finite control set model predictive control in power electronics," IEEE Transactions on Industrial Informatics, vol. 9, pp. 1003-1016, 2013.

[12] S. Vazquez, J. I. Leon, L. G. Franquelo, J. Rodriguez, H. A. Young, A. Marquez, et al., "Model predictive control: A review of its applications in power electronics," IEEE Industrial Electronics Magazine, vol. 8, pp. 1631, 2014

[13] S. Kouro, P. Cortés, R. Vargas, U. Ammann, and J. Rodríguez, "Model predictive control-A simple and powerful method to control power converters," IEEE Transactions on Industrial Electronics, vol. 56, pp. 1826-1838, 2009.

[14] P. E. Kakosimos, A. G. Kladas, and S. N. Manias, "Fast photovoltaic-system voltage-or currentoriented MPPT employing a predictive digital current-controlled converter," IEEE Transactions on Industrial Electronics, vol. 60, pp. 5673-5685, 2013.

[15] P. E. Kakosimos and A. G. Kladas, "Implementation of photovoltaic array MPPT through fixed step predictive control technique," Renewable Energy, vol. 36, pp. 2508-2514, 2011.

[16] M. B. Shadmand, R. S. Balog, and H. Abu-Rub, "Model predictive control of PV sources in a smart DC distribution system: Maximum power point tracking and droop control ", IEEE Transactions on Energy Conversion, vol. 29, pp. 913-921, 2014.

[17] S. Sajadian and R. Ahmadi, "Model Predictive Based Maximum Power Point Tracking for Gridtied Photovoltaic Applications Using a Z-Source Inverter."

[18] J. I. Metri, H. Vahedi, H. Y. Kanaan, and K. AlHaddad, "Real-time implementation of modelpredictive control on seven-level packed U-cell 